\title{
Clinical Communication with People who have Stroke Related Hemiplegia
}

\section{Robert Perna*}

Westside Neurorehabilitation Services, Lewiston, ME, England, UK

\section{Introduction}

Stroke is one of the leading causes of death and disability, and up to $80 \%$ of persons affected by stroke have hemiparesis or hemiplegia and related disability [1]. Hemiplegia takes considerable time and treatment to treat and often leaves individuals with long-term and often permanent motor and functional impairments. These impairments often change the person's self-esteem and self-concept. The loss of function is traumatic and requires grieving and perhaps reformulating of self-identity.

Many people who survive a stroke feel fear, anxiety, frustration, anger, sadness and a sense of grief over their physical and mental losses. These feelings are a natural response to the psychological trauma of stroke and uncertainty about the future. Some clinicians suggest that it can take 6 to 24 months to psychologically adjust to the effects of stroke [2]. As a result of the frequency and complexity of the psychological issues following stroke, the National Clinical Guideline for Stroke recommend that stroke teams should include a clinical psychologist [3].

Though this is a complex psychological and spiritual process, many individuals trying to cope with these losses and life changes does not get counseling or receive only brief counseling. Often the only stroke survivors that receive counseling are individuals with comorbid Major Depressive Disorder. Though depression is very common after stroke with an incidence of more than $25 \%$, most of the psychological issues people must deal with after stroke go unaddressed [3]. A few studies have investigated stroke survivor's self-perceptions [4,5] and found that stroke survivors perceived that sensory and motor impairment negatively affected their functional ability in daily activities, social roles and participation.

\section{Readiness to Talk about Hemiplegia}

Individuals with hemiplegia often communicate with various clinicians about prognosis and what can be done to promote functional recovery of the affected limb. These individuals often need a significant amount of education about various treatment options, care and protection of their affected limit and long-term issues such as spasticity and the various treatments for it. The individual may receive a diverse range of prognostic opinions that may run the whole spectrum from being overly positive and giving people false hope all the way to the other extreme which may be overly negative and cause someone to give up on therapy or become depressed from hearing a message they were not psychologically ready to hear. These issues are probably best explained through discussing real patient accounts. Mr. MJ is a 38 year old man who suffered a right middle cerebral artery stroke and had left non-dominant upper extremity hemiplegia. He was involved in multidisciplinary treatment and was discharged from occupational therapy at 8 months post stroke and was told that his limb would never be functional. He became angry and distraught. He explained to his psychologist that he was angry because he felt like his therapist had given up on his arm, before he was ready. He stated, "How do they know my arm won't come back?" MJ went on to explain that he was sad and felt depressed because he did not expect to hear this message and that he had been assuming it would eventually improve and become functional. A 28 year old woman (SA) who was 9 months post stroke was discharged from her occupational therapist and interpreted this as that she could no longer make any further recovery of her affected limb. She told the therapist. I used to be an athlete. I'm not done. This isn't me." A 45 year old construction estimator with right dominant hand hemiplegia at 4 months post stroke told his psychologist, "I can't believe my therapist is discharging me. I'm not ready for this" and "I need to keep working on my arm and I don't know what to do."

None of these individuals were ready to hear the messages they were given by their physical and occupational therapists, when delivering such important messages, it is essential that the communicating therapist consider the patients psychological readiness to hear the message as it is worded.

Therapist may want to consider conceptual models as a way to understand post stroke adjustment. There are various models that may be applicable though some clinicians and researchers suspect that available models over simplify the actual post-stroke adjustment experience. Wade et al. [6] described a model suggesting that people move through four stages: Crisis, Treatment, Realization, Adjustment and Acceptance. Some other psychological models can help understand how the patient is coping and if they are psychologically ready to hear and process the message the therapist is trying to give them. Two of the most important models in trying to understand post stroke adjustment are the Kubler-Ross stages [7] and the Transtheoretical Model and stages of change [8]. The Kubler-Ross [7] model suggests that when grieving losses, people go through five psychologically stages (Denial, Anger, Bargaining, Depression, and Acceptance) before they may settle in with a stable acceptance of their loss or situation. The first stage is denial, a stage in which people have no real understanding or insight into their losses and may not be open to direct messages about their loss. One of the great complexities of this model is that people may bounce around the stages for some time before progressing through them. This may cause some to look like they are at different stages at different time. It is also possible to get stuck in a stage, for example, someone may become persistently depressed or angry after their stroke. The Transtheoretical Model also has five stages (Precontemlplation, Contemplation, Preparation, Action and Maintenance). This model is often applied to assess someone's readiness for behavior change, but it also be applied to someone's level of readiness to accept stroke related impairments and work toward addressing them.

Psychologically important messages are only really accepted and understood when the message is delivered in a manner that the person is ready to hear. Sometimes the therapist working with a patient with hemiplegia will say, "I've already explained to BT that he has no activation and will have no further recovery." This may suggest a limited understanding of patient readiness for that message. The benefit of the

${ }^{*}$ Corresponding author: Robert Perna, RN, Ph.D., Westside Neurorehabilitation Services, Lewiston, ME, England, United Kingdom, Tel: 8643362534; E-mail: Dr.Perna@Juno.com

Received January 27, 2018; Accepted January 29, 2018; Published February 02 , 2018

Citation: Perna R (2018) Clinical Communication with People who have Stroke Related Hemiplegia. Int J Neurorehabilitation 5: e130. doi: 10.4172/2376$0281.1000 \mathrm{e} 130$

Copyright: $\odot 2018$ Perna R. This is an open-access article distributed under the terms of the Creative Commons Attribution License, which permits unrestricted use, distribution, and reproduction in any medium, provided the original author and source are credited. 
Citation: Perna R (2018) Clinical Communication with People who have Stroke Related Hemiplegia. Int J Neurorehabilitation 5: e130. doi: 10.4172/2376-0281.1000e130

aforementioned models is that a therapist ideally should compose the message based on the patient's stage or level of adjustment based on the stages. This will help promote effective communication and improved patient follow through with treatment related activities and self-care.

\section{References}

1. Luke C, Dodd KJ, Brock K (2004) Outcomes of the bobath concept on upper limb recovery following stroke. Clin Rehabil 18: 888-898.

2. Robertson J (2010) Psychological needs following stroke. Stroke presentation.

3. Royal College of Physicians (2008) National Clinical Guideline for Stroke (2008) Stroke: National clinical guideline for diagnosis and initial management of acute stroke and transient ischemic attack (TIA). National Institute for Health and Clinical Excellence.
4. Jørgensen TS, Wium-Andersen IK, Wium-Andersen MK, Jørgensen MB Prescott E, et al. (2016) Incidence of depression after Stroke and associated risk factors and mortality outcomes, in a large cohort of Danish patients. JAMA Psychiatry 73: 1032-1040.

5. Doyle SD, Bennett S, Dudgeon B (2014) Upper limb post-stroke sensory impairments: The survivor's experience. Disabil Rehabil 36: 993-1000.

6. Wade DT, Langton HR, Skilbeck CE, David RM (1985) Stroke: A critical approach to diagnosis, treatment and management. London: Chapman and Hall Medical. Warwick.

7. Kübler-Ross E (1969) On death and dying. The Macmillan Company, New York

8. Prochaska JO, Butterworth S, Redding CA, Burden V, Perrin N, et al. (2008) Initial efficacy of MI, TTM tailoring and HRI's in multiple behaviors for employee health promotion. Prev Med 46: 226-231. 